\title{
FROM MUSE TO MATERIAL: THE DEFIANCE OF HOMERIC IDENTITY THROUGH CREATIVE ADAPTATION
}

\author{
SARAH LEIDICH \\ I. Introduction

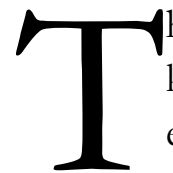 \\ he hero crossing the wine-dark sea, a king kneeling at the foot of his son's \\ killer, a boy defending his homeland in his father's absence. The world of \\ epic Greek myth is an alluring and vast web of heroic narrative and moral \\ dilemma. These iconic moments transcend history and cultural decay. They
} live in the literature, art, and philosophical framework of the contemporary human experience. Homeric myth is intrinsically embedded in our cultural landscape; it is the thread that runs through the most mundane storytelling and the most epic fantasy narrative. The narratives of the Iliad and The Odyssey have been institutionalized in the Western canon; they have been prescribed as the essential foundation of academic discourse.

Yet these same myths also include a daughter sacrificed by the hand of her father, a woman raped and held hostage by the greatest of the Greeks, and a girl whose beauty launched a thousand ships and killed even more men: Iphigenia, Briseis, and Helen. Iphigenia, Agamemnon's daughter, sacrificed in an offering to Artemis to bring back the winds for the Greek fleet's procession to Troy. Briseis, the prize at the center of the animosity between Agamemnon and Achilles. And Helen, a woman whose beauty was weaponized without her agency, for whom the Gods, the Trojans, and the Greeks blamed, scrutinized, and killed for. These women were persecuted, possessed, and discounted. Myth in any form reflects the cultural and societal norms of a community, and, as such, Greek myth embodies the deeply rooted hegemonic masculinity of antiquity.

Before exploring the response to the patriarchal structures of the Iliad in the $21^{\text {st }}$ century, it is crucial to establish how Homeric epics function as exclusionary texts. Which identities are celebrated? Which are scorned? And which are present, yet discarded? It is easy to establish the identities that are celebrated, such as the warrior, the king, and the fighter, all men who hold power through their birthrights and relationship to the gods. In the Iliad, these men are Achilles, Patroclus, Agamemnon, Ajax, and Odysseus. The celebrated female identities in the Iliad are those of the goddesses - Aphrodite, Artemis, Athena. What of the laywomen, women who are not gods, who are used as pawns in the constructed war? Helen, Briseis, Hecuba, and Andromache have minimal dialogue and almost no autonomy. These characters exist in relation to their male counterparts, stripped of agency and interiority. 
There is room, though, in the oeuvre of Homeric myth, for an elevation of otherwise silenced voices. As Columbia professor Gayatri Spivak identifies in her essay "Displacement and the Discourse of Women," women have continually operated in a patriarchal non-identity since the birth of antiquity, pushed to the sides and defined through the absence of male identity. Removed from existence as the subject, and relegated to a comparative other, "the discourse of man is in the metaphor of woman" (Spivak 169). The classics began this non-identity, and translations and literature since have perpetuated it. So, what, I ask, as a rapt and intrigued reader of the classics, should I find within these texts as a woman? How do the most central and core stories of the Western tradition speak to those who are not given agency in the original text? Spivak suggests that "the collective project of our feminist critique must always be to rewrite the social text so that the historical and sexual differentials are operating together" (Spivak 185). For women to embody actualized identity, there must be a rewrite of the foundational text. Emily Wilson, with her translation of The Odyssey, and Madeline Miller and Pat Barker, with their respective novels, The Song of Achilles and The Silence of the Girls, take a traditional Homeric epic and expand the narrative's accountability. While translation and adaptation are separate modes of literary reworking, both allow for authors to conceptualize a new meaning, intent, and effect of the original text. Through reimagining epic narratives such as the Iliad and The Odyssey, women authors transform exclusionary texts into stories that encompass the identities reflected in contemporary society.

\section{Translation as Revolution}

Throughout modern history, translation has been a field dominated by male academics. The most widely read translations of the epics are written by men. The translation of the Iliad I will be using in this essay is by Robert Fagles, as it is a perpetuation of the tradition of translation upheld by academic consumption. However, translation as performed by women inherently shifts the intimacy of these foundational narratives, if only through an othered identity reclaiming the text. In breaking from literary tradition, translation as a literary mode can serve as a radical reconfiguring of the societal implications of a text. Translation theorist Robert Shorrock writes that "translations are the products of the age into which they are born; they are not, however, prisoners of that age. Rather, they actively seek to make new, approaching the narrative with their own agendas, explicit or implicit, in order to shape and create a text that is relevant and readable for their own age" (Shorrock 448). This goal, the seeking of a new meaning from a previously established narrative, allows for translations to be "texts in their own right" (Shorrock 440).

In her book Gender in Translation, Sherry Simon illustrates how the union of identity and translation transforms meaning. She writes:

Meliora Vol. 1, Issue 1 
The process of translation must be seen as a fluid production of meaning, similar to other kinds of writing. The hierarchy of writing roles, like gender identities, is increasingly to be recognized as mobile and performative. The interstitial now becomes the focus of investigation, the polarized extremes abandoned. (Simon 13)

Translation must work to reshape meaning in relationship to identity. The "interstitial" that Simon speaks of is perhaps the most important space that will be explored in this thesis, especially as I begin to analyze the act of adaptation. However, before my analysis occurs, the radical nature of translation must be further unpacked.

Emily Wilson, who translated The Odyssey and was hailed as a feminist interpreter of the epic, recognizes the gendered constraints through which she navigated in her translation process. In her introduction, she tells her reader: "The gendered metaphor of the 'faithful' translation, whose worth is always secondary to that of the male-authored original, acquires a particular edge in the context of a translation by a woman of The Odyssey, a poem that is deeply invested in female fidelity and male dominance" (Wilson 86). This concept of fidelity must be subverted if a translation has something to say regarding the social and political dynamics of either contemporary life or antiquity. As Simon identifies, "For feminist translation, fidelity is to be directed towards neither the author nor the reader, but towards the writing project - a project in which both the writer and translator participate" (Simon 2). This commitment to the project, to the mutual effort of taking something new from a text to transform meaning, moves feminist translation past the institutional translation engrained in academia. In the most inherent way, a woman translating a traditionally patriarchal text is subversive.

While Wilson's act of translation is in defiance of the canon surrounding the classics, so too is her specific translations of the original Greek. In her introduction, Wilson writes:

I try to avoid importing contemporary types of sexism into this ancient poem...for instance, in the scene where Telemachus oversees the hanging of the slaves who have been sleeping with the suitors, most translation introduce derogatory language ('sluts' or 'whores'), suggesting that these women are being punished for a genuinely objectionable pattern of behavior, as if their sexual history actually justified their deaths. The original Greek does not label these slaves with any derogatory language. (Wilson 89)

Instead, Wilson uses the word "girls," removing the misogynistic and sexist assignment of guilt to the victim during this brutality demonstrated by Telemachus. The dismantling of the "gendered metaphor" allows for an honest and reflective translation of The Odyssey. 
The endeavor of translation, especially when aiming to uncover and examine identities subjugated in the original text, must serve as a vehicle for questioning intent and identity. Simon asks: "What does it mean to position translation within cultural studies? It means, principally, that the terms 'culture,' 'identity,' and 'gender' are not taken for granted but are themselves the object of inquiry" (Simon ix). This is both a "why' and the why. Why do things like "culture" and "identity" matter? And how do we adequately explore such vast and important topics? As translation becomes imbued in meaning, the act of translation draws nearer to that of adaptation. In the context of this exploration, adaptation is a sister to translation; both are acts of resistance that draw from concealed pockets of identity to reshape perception. Both translation and adaptation aim to rework narratives so as to speak to the present. Translation and adaptation exist as modes of interpretation that rebalance the integrity of existing narratives, and it is important to emphasize that translation and adaptation would not exist unless they pulled from something already existing in the original text — in this case, identities already in the text. These identities, namely feminine and queer identities, exist in the original story. Through this reconfiguring, marginalized identities finally have the chance to be visible and celebrated and the perpetuated erasure of identities comes closer to eradication.

\section{Women as the Prize}

Before looking at the radical reconfiguring of these epics, we must establish how women function in the original text. In the Iliad, women function as a muse and as property. This binary, between inspiration and ownership, limits female personhood in the original text. As previously established, the Fagles translation of the text remains a baseline translation and other than slight lyrical discrepancies, prioritizes the same masculine hierarchy that other translations of the text also do. The first line of the epic reads: "Rage-Goddess, sing the rage of Peleus' son Achilles" (Il.1.1). Here, female identity exists to convey the rage of man. Female personhood exists, in this context, as a vessel to "sing" the story of men.

Women's worth in the Iliad also stems from their appearance. The character of Briseis, a minor queen who is captured by Achilles during the Trojan War and who serves as the catalyst for the animosity between Achilles and Agamemnon, is depicted in terms of her looks. Briseis's descriptions in the text revolve solely around her beauty. Book I of the Iliad reads: "[Patroclus] let Briseis in all her beauty from the lodge / and handed her over to the men to take away" (Il.1.409-410). In the next book, Achilles agonizes over Briseis becoming Agamemnon's slave — "The brilliant runner Achilles lay among his ships / raging over Briseis, the girl with lustrous hair, / the prize he seized from Lyressus" (I1.2.784-786). Briseis's beauty is emphasized, but only in the broadest of strokes. She moves through the Greek camp "in all her beauty," and she has "lustrous hair," but there is nothing else the reader learns about 
her. The descriptions of her beauty are broad and opaque, just as her characterization is throughout the epic. She is something to be raged over, but there is no explanation why other than her appearance.

Women are also relegated to the status of an object throughout the rest of the poem, just as Briseis is referred to as "the prize," which exemplifies the nonidentity that Spivak identifies. At the very beginning of the epic, Achilles counters Agamemnon's desire to hold onto the priest's daughter, Chryseis. He says:

Whatever we dragged from towns we plundered, all's been portioned out. But collect it, call it back from the rank and file? That would be the disgrace. So return the girl to the god, at least for now. (Il.1.146-149)

The objects here — the "whatever," the "it" — are women. The subjugation of women manifests in the disregard of their personhood and relegation to disparate existence. The status of women in Homeric epics is a flawed one; the history of Homeric warriors taking spoils after defeating their enemy overwhelms any agency women could have had in this text.

Johnathan Ready, a Classics professor at the University of Michigan, illustrates the system of spoils present in the text while also illustrating the patriarchal influence on critical theory surrounding the Iliad. Ready focuses on the way spoils of war define status and societal order for Homeric heroes like Achilles. He writes: "A warrior expends his energies and risks death in exchange both for prizes that are doled out at the end of the day and for spoils he obtains on his own during the battle as well as after through transactions such as ransoming" (Ready 17). The taking of prizes was crucial in maintaining the engine of war. However, Ready fails to recognize that these spoils are women and girls. In the absence of thought, apparent in the original text and Ready's analysis, these identities are negated. Critical theory often fails to acknowledge female personhood, perpetuating the erasure of identity prevalent in the Iliad and academic theory surrounding the text.

However, as feminism and gender theory entered mainstream academia, the question of female personhood in the epics began to gain traction. Lin Foxhall, in her book Studying Gender in Classical Antiquity, tracks the evolution of this interest in women in the epics. Prior to the 1970s, women in antiquity received minimal attention. However, "the widespread discovery of women in antiquity in the AngloAmerican world...[follows] the rise of the women's movement in the late 1960s and early 1970s, in the atmosphere of so-called 'second-wave' feminism" (Foxhall 6). The absence of the identities that comprised present, modern life begged examination. As Foxhall writes:

Not only do we usually lack the direct voices of women, but slaves, lowstatus free people, foreigners, criminals, the disabled, children, the elderly and 
people with non-mainstream sexual identities are also largely silent (or silenced) in our surviving sources...But that does not mean we cannot listen for those other voices screaming through the silence. (Foxhall 16)

Marginalized identities exist in these texts, and these identities matter. Crucial here is Foxhall's identification that in the silence covering them, these voices are "screaming" for identification, examination, and literary tribute. Without the representation of the diverse identities found throughout these texts, the canon's homogeneity only reflects one kind of identity — that of a cisgender white man.

In her novel The Silence of the Girls, Pat Barker resoundingly amplifies the voices silenced in the original text in a novelized retelling of Briseis's story from her perspective. The publication of one novel may seem small, but it is revolutionary. The title itself speaks to the issue Barker addresses - the voices of the women in these foundational epics deserve to be elevated and embraced. The novel is wholly concerned with understanding Briseis's interiority. Her silence in the Iliad becomes an act of resistance in the novel. Her silence is her interiority, and her interiority is her power:

Would you really have married the man who'd killed your brothers? Well, first of all, I wouldn't have been given a choice. But yes, probably. Yes. I was a slave, and a slave will do anything, anything at all, to stop being a thing and become a person again. I just don't know how you could do that. Well, no, of course you don't. You've never been a slave. (Barker 132)

The narration in the novel occurs mostly through Briseis's thoughts, and the theme of the excerpt - bow could you do such a thing — runs throughout the novel. Barker's concern for female autonomy as a means of survival explores how and why women withstand the sexual and emotional violence inflicted on them by their captors. Barker is committed to salvaging female personhood, making sense of how women struggle to survive while enslaved. Barker's implementation of a questioning firstperson narration transforms the text to actively question and reflect on each moment of action in the story.

To illustrate Barker's revolutionary rewriting of the Iliad, let us visit the only moment Briseis speaks in the Iliad. After Briseis finds out about Patroclus's death, she embraces his body. Fagles's translation reads:

'So grief gives way to grief, my life one endless sorrow

The husband to whom my father and noble mother gave me, I saw him tom by the sharp bronze before our city, and my three brothers-a single mother bore us: my brothers, how I loved you! you all went down to death on the same day ... But you, Patroclus, you would not let me weep, 
not when the swift Achilles cut my husband down, not when he plundered the lordly Mynes' city—not even weep!

No, again and again you vowed

you'd make me godlike Achilles' lawful, wedded wife.' (Il.19.342-353)

In Fagles's translation, Briseis's dialogue stems from her position in relation to men. She grieves for "the husband" to whom she was given, and the "brothers" by which she's defined. The word she repeats is "not" - she was "not" allowed to weep, "not" allowed to grieve. In the emphasis of the negative, there is a negation of Briseis's existence. This one moment of interiority Briseis is offered in the original text relegates her personhood as relative to men.

However, Barker tackles this same moment with the intent of putting Briseis's personhood first. While Barker is not translating the original text, her reimagining of the moment offers a new interpretation of the moment. She writes:

I fell on my knees and clasped his cold feet in my hands. I think at that moment I felt more alone, more abandoned, than I'd ever felt. I wept without restraint and the other women, hearing my cries, came running out of the huts to mourn with me. I think we were all, to some extent, using Patroclus's death as a cover to mourn our own losses. I thought about my brothers as I wept. I even thought about poor, silly Mynes, who'd have been perfectly happy, I think, with another wife. But I wouldn't like it to be thought our grief for Patroclus was in any way staged, or insincere. I held his cold feet in my hands and remembered how he'd once told me not to cry, that he'd promised to make Achilles marry me. Oh, I've no doubt that on the battlefield, in the thick of the fighting, he was every bit as ferocious as the rest of them, but here in the camp, among the captive women and their children, he had always been kind. (Barker 228)

In a subversion of the original text, Briseis does not speak. Instead, we are offered a deep look at her interior thoughts as she begins to grieve the one man who was always kind to her. The agency imbued in her character, through phrasing that focuses on the "I" and the delicate remembrance of her past, prioritizes her personhood over the men surrounding her. Here, Briseis also becomes a vehicle of catharsis for all of the women oppressed in this epic. This visual, of the "other women" who "came running out of the huts to mourn with" Briseis, creates a poignant sense of unity. The husband emphasized so deeply in Fagles's translation is deemed "poor" and "silly." The elevation of Patroclus's goodness comes, in Barker's adaptation, from how well he treated "the captive women and their children."

Barker offers the women of the Iliad a platform in her novel. Her response to the epic's tradition re-centers female personhood, creating a narrative that stands in opposition to the source. Yet Barker also embraces the iconic characters of the source text. Achilles and Patroclus are still depicted as complicated and intriguing

Meliora Vol. 1, Issue 1 
warriors. Agamemnon's difficulties and warped rule appears throughout the novel. The bones of the narrative remain the same. But, as Foxhall writes, we are now able to listen "for those other voices screaming through the silence" (Foxhall 16).

\section{Poly Philtatos: The Most Loved by Far}

In the ancient Greek version of the Iliad, Achilles calls Patroclus poly philtatos. This roughly translates to "the most loved by far" (Woodard 64). Patroclus, in mainstream translations of the epic, functions as Achilles's companion, cousin, or best friend. The crux of this perpetuation of the heteronormativity surrounding this text is the term "companion," which has been straight-washed by scholars to mean "cousin" in Anglocentric representations of the text. Classics professor Madeleine Miller, in her novel The Song of Achilles, works to dismantle the dominant heterosexual narrative. In her novel, Achilles and Patroclus are depicted as lovers, exemplifying the meaning of poly philtatos.

Literary theorist Tony McKenna, in his essay "The Song of Achilles: How the Future Transforms the Past," illustrates the foundation of homosexuality in the original epic. He writes:

All of this, one feels, is somehow immanent in Homer's original, but the very forms and structures of social existence of the great poet's time forbade him from rendering explicit because history, and concomitantly, the historical characterization of a fictional character was something which, of necessity, remained invisible to his eyes. (McKenna 95)

This circles back to what lies in the interstitial. Why would Achilles mourn Patroclus like a husband grieving a wife? Why is Patroclus important enough for Achilles to shift the tides of the Trojan war over his death? What does the empty space in the original text offer to contemporary readers?

Foxhall identifies the cycles of oppression that affect the characters present in the text. She writes: "it was not just that women are oppressed. Rather, the idea of hierarchized gender relations could be used as a tool to oppress and objectify a whole range of groups" (Foxhall 12). The identity oppressed, in the patriarchal heteronormative tradition of the classics, is the queer identity. As Foxhall illustrates:

Gendered behavior of the Greeks in particular, especially male homoerotic relationships and pederasty, encountered a more mixed response among nineteenth-and earlier twentieth-century scholars: from their point of view, at least the Romans had the good grace to say they disapproved of such sexual encounters, even if it was clear that many Romans actually engaged in them. (Foxhall 4) 
The post-classical stifling of the identity, both queer and feminine, is dismantled in Miller's novel. Like Barker, Miller puts Briseis at the center of her narrative. And, while Barker maintains the ambiguity of Patroclus's and Achilles' relationship, Miller celebrates and elevates their love story. This story is something we have seen before; Ancient Greeks like Plato and Aeschylus identify the sexual relationship between these two men as divinely appointed. Yet, in Fagles's translation of the text, Achilles grieves the loss of his supposed friendship, calling Patroclus merely his "comrade." He says: "My dear comrade's dead- / Patroclus- the man I loved beyond all other comrades, / loved as my own life-I've lost him-Hector's killed him.../ My spirit rebels — I've lost the will to live." (Il.18.94-96). This heartbreaking moment illustrates the love that innately exists in the original poem. Achilles "loved" Patroclus. Without Patroclus, Achilles has "lost the will to live."

Miller takes this sentiment, present in the epic, and constructs a moving novel around it. In doing so, she acknowledges and celebrates a homosexual relationship. The structure exists, as demonstrated by the lovelorn language of Achilles, in the original text. By creating something new from that structure, and perhaps returning to the original intent, Miller invites her readers to reexamine the foundational text of the Iliad, in which Achilles continuously calls Patroclus "my Patroclus" (Il.18.121). Miller's text is a rich reworking of the Iliad that intervenes in the straight-washed and misogynistic translations of the Iliad. In the original Homeric epic, Achilles and Patroclus are buried together in the same urn. In following the emotions present in the original, Miller adapts her source text into a story that ends with the lines: "In the darkness, two shadows, reaching through the hopeless, heavy dusk. Their hands meet, and light spills in a flood like a hundred golden urns pouring out of the sun" (Miller 369).

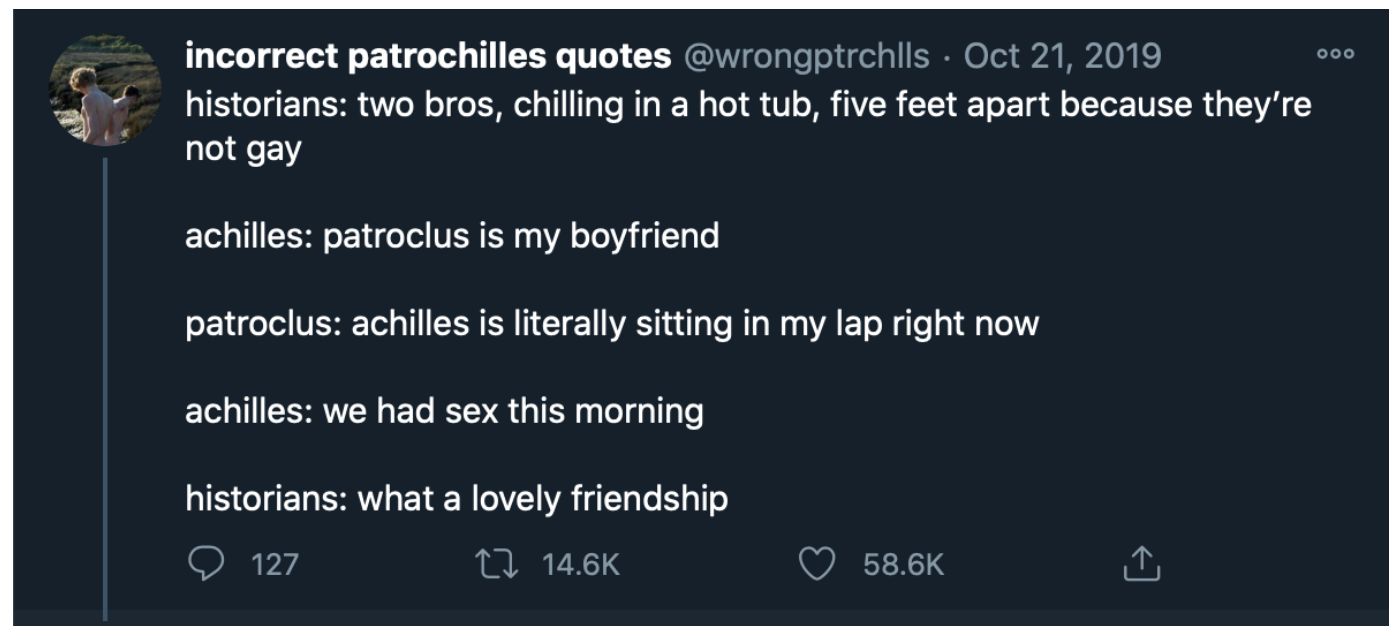

Meliora Vol. 1, Issue 1 


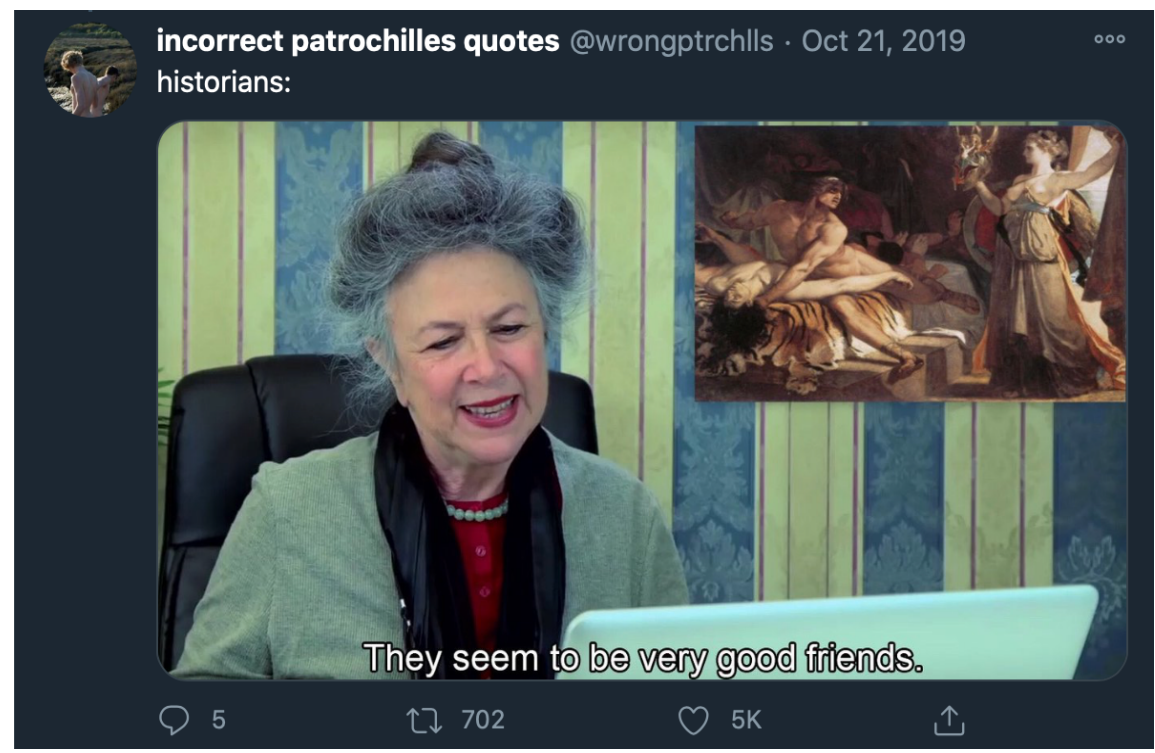

Figure 1: A tweet acknowledging the historical straight-washing of Achilles and Patroclus (@wrongptrchlls).

Perhaps the most remarkable function of The Song of Achilles comes in the response to the novel. Readers love this book, suggesting that the identities this novel celebrates imbue meaning into readers' own modern identity. The Twitter account Incorrect Patrochilles Quotes has over 20,000 followers and is entirely devoted to The Song of Achilles. In celebration of the relationship between Patroclus and Achilles, the admins of the account put these beloved characters into comical situations. One tweet, about historians identifying Achilles and Patroclus as "very good friends" despite them announcing their love, has 58,000 likes (@wrongptchlls). This tweet, while comedic, expresses the frustration of a community whose identity has been previously disregarded.

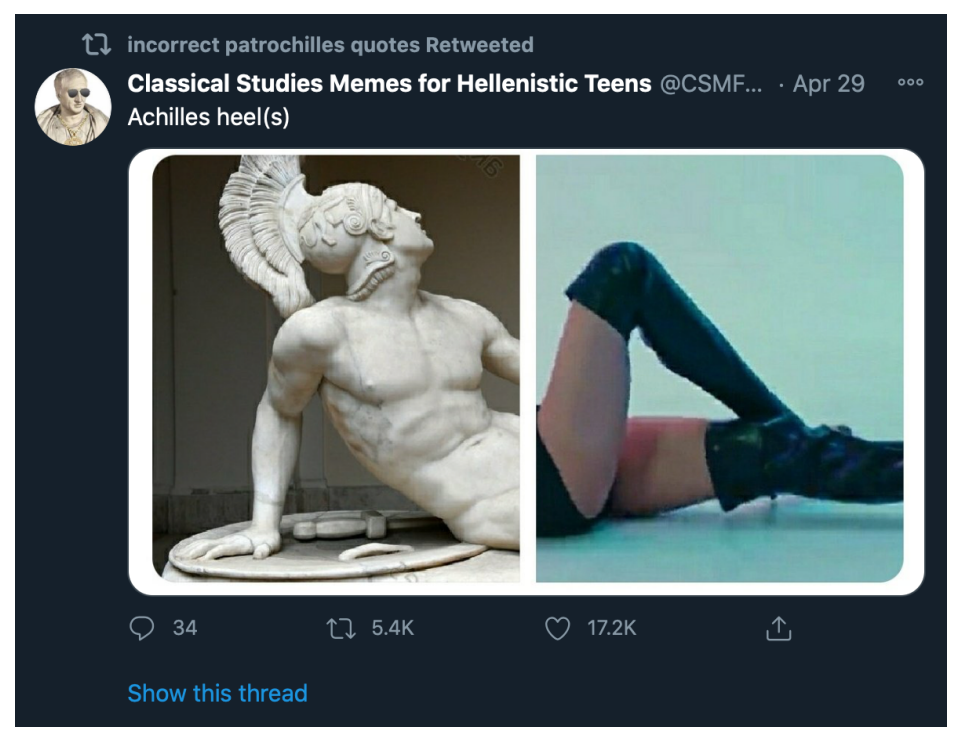

Stunningly, Achilles has also become a gay icon on the internet because of The Song of Achilles. One viral tweet, from Classical Studies Memes for Hellenistic Teens, riffs off of "Achilles' heel" and illustrates how the queer community has embraced these characters.

Figure 2: The top half of Greek bust clipped together with a pair of high heeled boots for the lower half, labeled 'Achilles heel(s)' @CSMFHT). 
Miller's adaptation has transcended its original form and taken on a virtual life of its own. Her amplification of marginalized voices has inspired readers and created an internet subculture. In a study on LGBT literature and young adult readers, researcher Caroline Blackburn found that "exploring possibilities of sexual and gender identities that are multiple, variable, and fluid might alleviate some of the pressure of being or becoming someone who is socially acceptable and soothe the anxieties with being or becoming someone who is not" (Blackburn 11). Queer literature like The Song of Achilles truly has the ability to transform self-perception and perception of others.

\section{The Past as Transformed by the Future}

As contemporary readers, we are familiar with the tropes and themes of the Iliad and The Odyssey. They appear throughout the literature, media, and storytelling that drives contemporary culture. However, both epics perpetuate the erasure of certain identities - namely, the feminine and sexually fluid. These narratives sit well within the patriarchal tradition and leave little room for empowerment or identification unless you are a cisgender straight man.

However, through the radical acts of translation and adaptation, new meaning and intent can be gleaned from these classical texts. Translation itself is revolutionary, and through translational theory, it is clear that translation creates new, and profound reflections on the original narrative. Even more revolutionary are the women working in translation today. Emily Wilson, translator of The Odyssey, dignifies identities that male translators may be unable to recognize. For a translation to impact the social and cultural attitudes of the present, the translation must look to identities obscured by the biases of previous translators.

Adaptation, as well as translation, serves as a vehicle for literary resistance and empowerment. Female personhood, in particular, can be elevated through adaptation. Second-wave feminism has given authors and creators the tools to identify lapses in ancient source material. In The Silence of the Girls, Pat Barker creates a feminist Iliad, not just through centering women, but also through providing them with interiority. Her accurate and brutal depiction of war heightens the magnitude of the emotion in her novel, and illustrates the power and endurance of women.

Just as The Silence of the Girls empowers female identity, The Song of Achilles has radically reshaped readers' responses to Homeric epics. In creating an openly queer novel, Madeleine Miller has offered the classics up to a new age of readers and consumers. Through her commitment to exploring the possibilities of the original text, Miller amplifies love above heteronormativity.

The themes and theories explored in this reflection could be dissected in greater detail. The issues of patriarchy, authority, gender, and heteronormativity in canonical texts and in their translation and adaptation warrant a more substantial 
project and deeper investigation. Can translation hold even greater power? The minutiae of words and language hold immense possibility, and a line-by-line comparison between institutional translations of The Odyssey with Emily Wilson's Odyssey could illuminate the way a translator's identity shapes a translation. Or, perhaps, a translator from a historically marginalized identity group could push the translator to a fairer, more honest translation.

With the adaptations of The Silence of the Girls and The Song of Achilles, scene-by scene-breakdowns of each novel could elucidate the strengths and weaknesses of contemporary fictional literature as compared to the epics. There is a thrill in seeing marginalized identities centered in mainstream literature, and the exploration can be endless.

This essay does not even begin to broach adaptations of the classics that diverge from close recreation of the narratives. The films, albums, and artwork that tackle the same themes and stories contained in the Iliad and The Odyssey offer an even deeper examination of contemporary reflection. As art shifts to virtual mediums, the possibilities for endeavors that embrace identity throughout antiquity grow limitless. The vast realm of adaptation and translation inspires me to search for the narratives that reflect my own reality. And, as identity becomes reflected in the literature we consume, storytelling begins to fulfill its true purpose - offering refuge, recognition, and revelation to its readers.

\section{WORKS CITED}

Barker, Pat. The Silence of the Girls. Thorpe, Charnwood, 2019.

Blackburn, Mollie V., et al. "Examining Queer Elements and Ideologies in LGBT-

Themed Literature: What Queer Literature Can Offer Young Adult Readers.” Journal of Literacy Research, vol. 47, no. 1, Mar. 2015, pp. $11-48$.

@CSMFHT. "Achilles heel(s).” Twitter, CSMFHT. 29 Apr. 2020. 4:49am, https://twitter.com/CSMFHT/status/12554491475677266 02. 16 Apr. 2021.

Foxhall, Lin. Studying Gender in Classical Antiquity. Cambridge University Press, 2013.

Homer, Emily R. Wilson, and Homer. The Odyssey. First edition. New York ; London: W.W. Norton \& Company, 2018. Print.

Homer., Robert Fagles, and Bernard Knox. The Iliad. New York, N.Y.: Penguin Books, 1998. Print.

McKenna, Tony. "The Song of Achilles: How the Future Transforms the Past." Art, Literature and Culture from a Marxist Perspective. Palgrave Macmillan, 2015. 
Miller, Madeline. The Song of Achilles. Bloomsbury, 2017.

Ready, Jonathan L. "Toil and Trouble: The Acquisition of Spoils in the Tliad." Transactions of the American Philological Association (1974-), vol. 137, no. 1, 2007, pp. 3-43. JSTOR.

Shorrock, Robert. "The Values of Translation: Contestation and Creativity in Homer's English "Iliads." International Journal of the Classical Tradition, vol. 10, no. 3/4, 2003, pp. 438-453.

Simon, Sherry. Gender in Translation: Cultural Identity and the Politics of Transmission. Psychology Press, 1996.

@wrongptchlls. "They seem to be very good friends." Twitter, @wrongptchlls, $29 \quad$ Oct. 2019, 2:15pm, https://twitter.com/wrongptrchlls/status/1186375552548122624, 16 Apr. 2021.

SARAH LEIDICH, Barnard College '21, is an English and film major born and raised in Boulder, Colorado. She loves writing, storytelling, and adaptation in any form. When not in the classroom, Sarah can be found taking advantage of New York's culinary and theatre scenes. 